\title{
$A b$ Initio Study of the Complexation Behavior of Calix[5]arene Derivative toward Alkyl Ammonium Cations
}

\author{
Jong-In Choe, Suk-Kyu Chang, Minamino Satoshi, ${ }^{*}$ and Shinkoh Nanbu ${ }^{\dagger}$ \\ Department of Chemistry, Chang-Ang University, Seoul 156-756, Korea \\ "Institute for Holectilar Science, Mvodaij, Okazaki, Aichi 4+4-8585, Japan \\ Received Aughst 12, 2002
}

\begin{abstract}
The structures and complexation energies of penta-O-alkylated $\mathbf{1 b}$ and penta-O-tert-butyl ester le of $p$-tertbutylcalix[5] arene and their simplified structures (2b and $2 \mathrm{e}$ ) toward a series of alkyl anmonium guests have been calculated by a semi-empirical AMl method. For AMl calculations, complexation efficiencies of the simplified host $2 \mathrm{e}$ are very similar to the values of host $1 \mathrm{e}$. The complexes of simplified host $2 \mathrm{e}$ with alkyl ammonium ions also have been optimized by ab initio $\mathrm{HF} / 6-31 \mathrm{G}$ method. The calculated complexation efficiencies for $2 \mathrm{e}$ by $a b$ initio method have been found to be bigger in magnitude than the values obtained by AMl calculations for linear alkyl ammonium guests. Calculation results show that all of the calix[5]aryl derivatives investigated in this study have much better complexation ability toward ammonium cation without alkyl group compared with other alkyl ammonium guests. Ab initio calculations also well duplicate the molecular discriminating behaviors of calix[5]arene derivative $2 \mathrm{e}$ between butyl ammonium ions: $n-\mathrm{BuNH}_{3}{ }^{+}$ $>$ iso $-\mathrm{BuNH}_{3}{ }^{-}>\sec -\mathrm{BuNH}_{3}^{-}>$tert $-\mathrm{BuNH}_{3}^{-}$.
\end{abstract}

Key Words : Calix[5]arene. Alkyl ammonium ion. Molecular recognition. $A b$ initio $\mathrm{HF} / 6-3 \mathrm{lG}$

\section{Introduction}

Calixarenes $^{1.2}$ have received much attention recently as one of the most widely employed molecular frameworks for the construction of many versatile supramolecular systems. ${ }^{3.4}$ Among the varying structures of calixarenes. pentameric analogue calix[5] arene has received relatively less attention due to difficulties encountered both in its sy'nthesis and selective derivatization compared with other widely employed calixarenes having four. six. or eight repeating units. However. a series of calix[5] arene derivatives having crown ether or ester functions has been prepared and is known to have strong affinity toward large alkali metal ions. "Selective recognition of organic ammonium guests is very important for many functional biogenic ammonium ions. and a number of sophisticated host sy'stems are derived from calixarenes. ${ }^{6-9}$ For calix[5] arene based amine selective ionophores. selective endo-calix complexation of alkyl ammonium cations by functionalized (1.3)-p-tert-butylcalix[5]crown ether ${ }^{16}$ and by calix[5]arene-based molecular vessels $\mathbf{1 b}-1 \mathbf{e}^{1 \mathrm{l}}$ have been reported. Giannetto et $a t$. report very efficient discrimination behavior between butylammonium isomers by means of calix[5]arene-based ion selective electrode technique. ${ }^{12}$ More recently: 1.3-bridged calix[5]crown-6-ether was investigated as a tool for the shape recognition of alkylammonium ions in focusing the endo-versus exo-cavity complexation. ${ }^{13}$ These interesting host-guest properties are mainly related to the calix[5]arene backbone fixed in cone-type $C_{S_{5}}$-symmetric structure by providing a highly preorganized three dimensional molecular framework assembled as efficient binding sites.

"To whom correspondence should be addressed. Phone: +82-2820-5200, Fax: $+82-2-825-4736$. e-mail: choejia $a$ cau.ackr
Parallel to this. a lot of computational studies have been performed for the supramolecular systems of calixarenes and their complexes. ${ }^{1+}$ We previously reported the computer simulations on the molecular recognition of butylamines by ester derivative of p-tert-butylcalix[5]arene. using several molecular modeling programs of AM1 semi-empirical and molecular mechanics. ${ }^{15}$ The results show that $n$-butyl ammonium guests generally have larger complexation affinity over other branched butyl ammonium ions. Trends of these calculations in vacuum agree well with the published experimental ${ }^{1 l}$ results in the following order: $1 \mathrm{e}>1 \mathrm{~b}>1 \mathrm{c}>1 \mathrm{~d}$.

Studies of the p-tert-butylcalix[4]crown-6-ether and its alkyl anmonium complexes show that cone conformation is the most stable for all the emplored calculation methods. ${ }^{16}$ In this paper. we have calculated the molecular recognition behaviors of penta-O-alkylated derivative $\mathbf{1 b}$ and tert-butyl ester derivative 1e of cone-shaped p-tert-butylcalix[5] arene and their simplified structures (2b and $\mathbf{2 e}$ ) toward a series of alkyl anmonium guests by semi-empirical AMl method. The host $2 \mathrm{e}$ (methyl calix[5]aryl ester) is a trimmed version of host 1e (tert-butyl p-tert-butylcalix[5]anyl ester) for the purpose of ab initio $\mathrm{HF} / 6-31 \mathrm{G}$ optimization. The main emphasis of this research is determining the selectivity of the host for different alkyl ammonium guests with varying structural characteristics. which are good model compounds for the biologically important organic amine guests. The calculation results might provide a deeper insight into these relatively less well studied but interesting molecular frameworks of calix[5]arenes.

\section{Computational Methods}

The initial structures of host and guest molecules were 


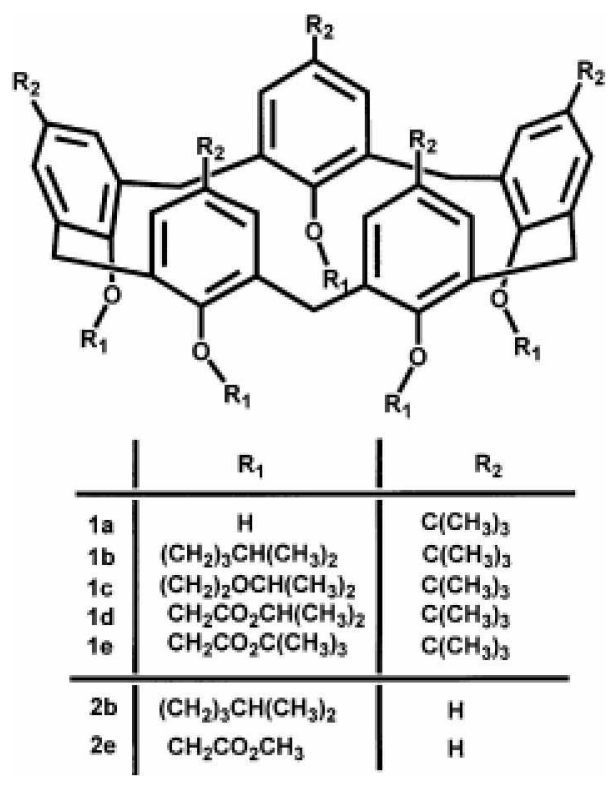

Figure 1. Chemical structure of calix[5] arene denvatives.

constructed by HyperChem. ${ }^{17}$ To find optimized conformations. we executed a conformational search by simulated annealing method. which has been described in a previous publication. ${ }^{16 \mathrm{a}}$ The structures of the hosts $1 \mathrm{~b} .1 \mathrm{e} .2 \mathrm{~b} .2 \mathrm{e}$. and their complexes obtained from $\mathrm{MM} / \mathrm{MD}$ calculations of HyperChem and InsightII/Discover ${ }^{1 \S}$ were fully' re-optimized to estimate the binding energies and the enthalpies of formation for the compounds. using the AMl method. To confirm that the final structure is in the local minimum point. we have calculated the nomal mode frequencies of the optimized complex. Each vibrational spectnum shows no negative value of frequency. which suggests that the optimized structure is really in minimum point. Ab initio $\mathrm{HF} /$ 6-31G optimization of host 2e or its complex by Gaussian 98 on a Fujitsu VPP 5000 supercomputer at Okazaki National Research Institute of Japan took more than 100 hours to reach an optimum conformation for each complex. Initially: we tried to calculate the host $1 \mathrm{e}$ with guest ions. but this complex was too big to be optimized by ab initio $\mathrm{HF} / 6-31 \mathrm{G}$ method using the supercomputer. Therefore. we had to change the tert-butyl group in the upper rim of calix|5|arene to hydrogen atom and the tert-butyl group in the ester branch to methyl group. This way. host $2 \mathrm{e}$ has the same basic skeleton of calix $|5|$ arene as the smaller substituent as opposed to host le without significantly affecting the basic binding site of $1 \mathrm{e}$.

\section{Results and Discussion}

There might be a variety of conformational isomers in ether and ester derivatives of calix $|5|$ arene. depending on the degree and nature of substitution. ${ }^{19}$ Among them. penta-Oalkylated $p$-tert-buty lcalix $\mid 5$ |arenes frozen in $C_{S \mathrm{v}}$-symmetric cone conformation have received much attention as one of the most efficient and selective synthetic neutral molecular receptors for linear alkylamımonium ions. ${ }^{10}$ As we discussed in a preliminary report. ${ }^{15}$ we have focused our efforts on the most stable endo-cone-shaped complexes of hosts with various alkyl ammonium ions.

Semi-empirical (AM1) Method. The confomations of the host and complexes obtained from MM calculations were fully re-optimized to estimate the binding energies and the enthalpies of formation for the complexes. using the AM1 seni-empirical method. Since the binding energy and the enthalpy of formation are directly connected for the calculation of complexation energy, the complexation energy ( $\mathrm{E}_{\text {Complex }}-\mathrm{E}_{\text {Host }}-\mathrm{E}_{\text {Guest }}$ ) is exactly the same as the complexation enthalpies $\left(\Delta \mathrm{H}_{\text {Complex }}-\Delta \mathrm{H}_{\text {Hust }}-\Delta \mathrm{H}_{\text {Guest }}\right)$. Therefore. we report only the values of the calculated enthalpy. Table 1 summarizes the calculated enthalpies of formation and the relative complexation efficiencies of the hosts with various alkyl ammonium cations.

In Table 1, the data more meaningful than the individual enthalpies are in fact the complexation enthalpies $\left(\Delta \mathrm{H}_{\text {Complex }}\right.$ $\left.-\Delta \mathrm{H}_{\mathrm{H} \text { sst }}-\Delta \mathrm{H}_{\mathrm{Gu} u s \mathrm{~s}}\right)$ to cancel out the individual guest effects for the different alkyl anmonium cations. The hosts $\mathbf{2} \mathbf{b}$ and $2 \mathrm{e}$ (methyl calix|5|aryl derivative) are trimmed structures of host $\mathbf{1 b}$ and 1e (tert-butyl p-tent-butylcalix|5|arỵl ester) having the same basic structural unit comprising possible

Table 1. AMl Enthalpies ( $\mathrm{kcal} / \mathrm{mol})^{a}$ of Complexes of Calix[5]arene with Alkyl Ammonium Ions

\begin{tabular}{|c|c|c|c|c|c|c|c|c|c|c|}
\hline \multirow{3}{*}{\multicolumn{3}{|c|}{$\begin{array}{l}\text { Semi-empirical } \\
\text { AMl enthalpies } \\
\text { using HyperChem }\end{array}$}} & \multicolumn{8}{|c|}{ Alkt l ammonium guest } \\
\hline & & & $\mathrm{NH}_{4}^{-}$ & $\mathrm{Me}$ & Et & $n-\mathrm{Pr}$ & $n-B y^{r}$ & iso-Bur & $\sec -\mathrm{Bu}^{c}$ & $\operatorname{ten} t-\mathrm{Bu}^{c}$ \\
\hline & & & 150.53 & 148.65 & 138.57 & 131.17 & 123.53 & 125.01 & 124.33 & 125.40 \\
\hline \multicolumn{2}{|c|}{ Host } & Guest & \multicolumn{8}{|c|}{ Complexes with host } \\
\hline-307.77 & Host 1b & $\mathrm{RNH}_{3}^{+}$ & -226.00 & -219.15 & -225.76 & -231.72 & -238.85 & -237.30 & -234.15 & -226.23 \\
\hline-619.32 & Host 1e & $\mathrm{RNH}_{3}^{+}$ & -545.24 & -535.22 & -539.85 & -545.54 & -552.74 & -550.14 & -538.05 & -534.36 \\
\hline-215.68 & Host $2 b$ & $\mathrm{RNH}_{3}^{+}$ & -129.46 & -124.00 & -130.68 & -136.45 & -144.03 & -142.02 & -139.16 & -131.57 \\
\hline-471.89 & Host $2 \mathrm{e}$ & $\mathrm{RNH}_{3}^{+}$ & -394.09 & -386.62 & -389.99 & -395.47 & -402.62 & -399.42 & -394.32 & -387.23 \\
\hline \multicolumn{3}{|c|}{ Host $\mathbf{1 b}+$ Guest complexation ${ }^{d}$} & -68.76 & -60.03 & -56.56 & -55.12 & -54.61 & -54.54 & -50.71 & -43.86 \\
\hline \multicolumn{3}{|c|}{ Host le + Guest complexation ${ }^{d}$} & -76.45 & -64.55 & -59.10 & -57.38 & -56.95 & -55.83 & 43.06 & -40.44 \\
\hline \multicolumn{3}{|c|}{ Host $2 b+$ Gluest complexation $^{d}$} & -64.31 & -56.97 & -53.57 & -51.94 & -51.88 & -51.35 & -47.81 & -41.29 \\
\hline \multicolumn{3}{|c|}{ Host $2 \mathrm{e}+$ Guest complevation } & -72.73 & -63.38 & -56.67 & -54.75 & -54.26 & -52.54 & -47.21 & -40.74 \\
\hline
\end{tabular}

"Error limits in these calculations are $0.01 \mathrm{kcal}$ mol. ${ }^{\mathrm{M}} \mathrm{Me}=$ methyl ammonium. Et $=$ ethyl ammonim. $n-\mathrm{Pr}=n$-propyl ammonium, $n$-Bu $=n$-buttyl

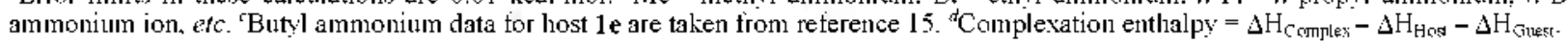




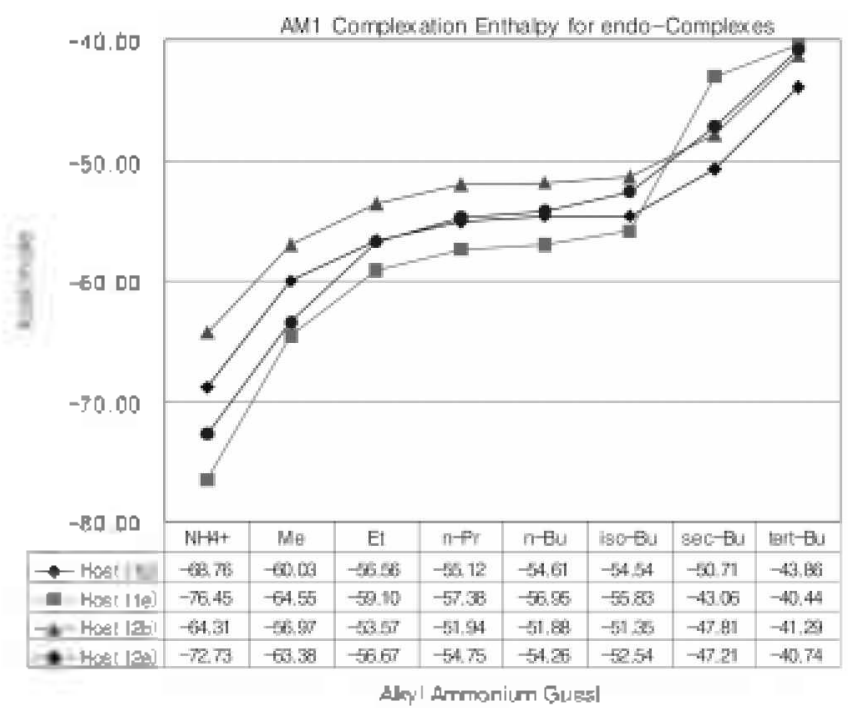

Figure 2. Plot of AMl complexation enthalpies for endocomplexes of hosts.

binding sites of upper rim cavity and lower rim ester and ether functions.

To compare the complexation efficiencies for the alkyl ammonium guests in various calix[5]aryl hosts. we have converted the complexation energy data in Table 1 into a plot (Figure 2). When one sees the graphs in Figure 2 , it is very clear that the trend of the complexation efficiencies for the trimmed host $2 \mathrm{e}$ with alkyl ammonium ions is very similar to that of host le in the order of $\mathrm{NH}_{4}{ }^{-}>\mathrm{MeNH}_{3}{ }^{+}>\mathrm{EtNH}_{3}{ }^{+}>n$ $\mathrm{PrNH}_{3}^{+} \sim n-\mathrm{BuNH}_{3}^{-}>$iso- $\mathrm{BuNH}_{3}^{-}>\sec -\mathrm{BuNH}_{3}^{-}>$tert$\mathrm{BuNH}_{3}^{+}$. Among the butylammonium ions. the complexation affinity decreases drastically from $n$-butyl to other isomeric butyl ammonium ions due to steric hindrance of the bulky substituents. The calculated results confirmed the earlier suggestion of the efficient discrimination of butyamine isomers by calix[5] arene based ether ionophore $\mathbf{l b}$ by ISE technique. In In that report the complexed $n$-butylammonium guest is depicted as efficiently interacting with the preorganized ether oxygen atoms of $\mathbf{1 b}$. with its alkyl group pointing toward upper rim cavity of calix[5]arene. With this structure. the role of the carbonyl function seems to be relatively less important than the ether oxygen donor site in the complexation of alkyl ammonium guests. The complexation efficiencies of the trimmed host $2 \mathbf{b}$ with alkyl ammonium ions also show a similar trend to those of host 1b. Therefore it can be generalized that the complexation efficiency decreases gradually as the size of the alkyl group increases. The calculation results for $1 \mathrm{e}$ and $2 \mathrm{e}$ clearly suggest that the presence of $p$-tert-butyl groups in the upper rim of host le does not affect significantly the relative stability of the host-guest complexes in the present calix[5]arene systems.

Ab Initio HF/6-31G Method. As we mentioned in the "Computational Methods" section. we could not calculate the whole structure of the host 1e due to the memory size. but fortunately the smaller calix[5]aryl ester $2 \mathrm{e}$ could be optimized using the HF/6-31G method.

Table 2 summarizes the $a b$ initio energies and the complexation efficiency of host $2 \mathbf{e}$ with various alkyl ammonium cations. To compare the complexation efficiency of the AMl semi-empirical method with $a b$ initio $\mathrm{HF} / 6-31 \mathrm{G}$ calculation for host $2 \mathrm{e}$. we have converted the complexation data of host $2 \mathrm{e}$ in Tables 1 and 2 into a plot of Figure 3. When one sees the graphs in Figure 3. the trend of the complexation energies for host 2e, using ab initio HF/6-31G method is similar to that of host $2 \mathrm{e}$ with AM1 semi-empirical calculations. But. the complexation energies calculated by ab initio method is $10-17 \mathrm{kcal} / \mathrm{mol}$ bigger in magnitude than those by AMl calculation for alkyl ammonium ions. except for tertbutyl ammonium.

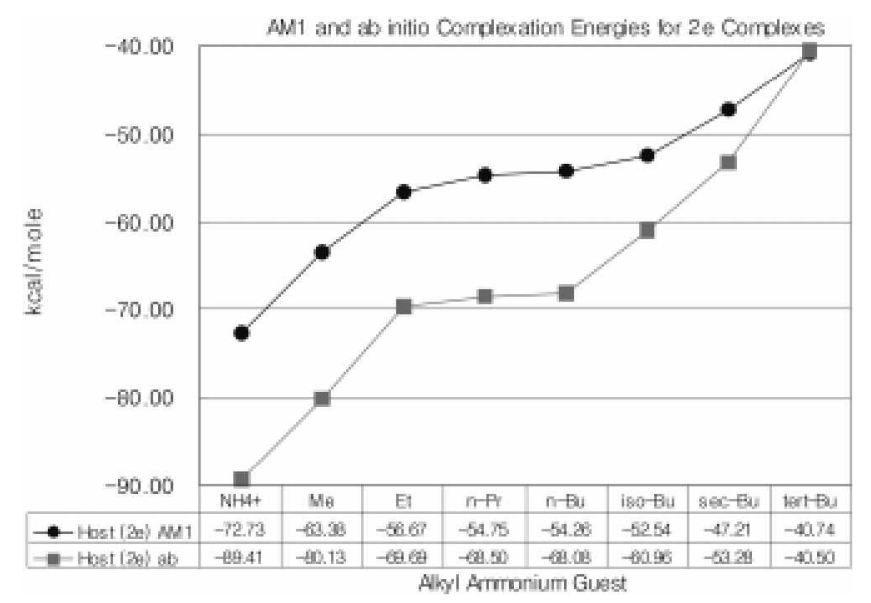

Figure 3. Plot of AMl and $a b$ initio complexation energies for endo-complexes of host $2 \mathbf{e}$.

Table 2. Ab initio HF/6-3 IG Energies (A.U. $)^{a}$ of Difterent Complexes of Calix[5]arene with Alkvl Ammonium Ions

\begin{tabular}{|c|c|c|c|c|c|c|c|c|c|}
\hline \multirow{3}{*}{\multicolumn{2}{|c|}{$\begin{array}{c}. A b \text { initio } \\
\mathrm{HF} / 6-31 \mathrm{G} \text { energies } \\
\text { Using Gaussian } 98\end{array}$}} & \multicolumn{8}{|c|}{ Alkyl ammonium guest } \\
\hline & & $\mathrm{NH}_{4}^{-}$ & $\mathrm{Me}$ & Et & $n$-PI & $n-\mathrm{Bu}$ & iso-Bu & $s e c-\mathrm{Bul}$ & tent-Bu \\
\hline & & -56.5159 & -95.5388 & -134.5658 & -173.5862 & -212.6057 & -212.6063 & -212.6111 & -212.6172 \\
\hline Host $2 \mathrm{e}$ & Guest & \multicolumn{8}{|c|}{ Complexes with host } \\
\hline$-304+1610$ & $\mathrm{RNH}_{3}^{+}$ & -3100.8194 & -3139.8275 & -3178.8378 & -3217.8529 & $-\$ 2568751$ & -32568644 & -3256.8570 & -3256.8428 \\
\hline \multicolumn{2}{|c|}{$\begin{array}{l}\text { Host } 2 \mathrm{e}+\text { Guest } \\
\text { complexation entergy }\end{array}$} & -89.4145 & -80.1284 & -69.6833 & -68.4953 & -68.0851 & -60.9592 & -53.2837 & -40.4973 \\
\hline
\end{tabular}

"Error limits in these calculations are about $2 \times 10^{-5}$ A.U. Units tor the ab initio total energies are in A.U... and units for complexation energies are in kcal mol using conversion factor 1 A.U. $=627.50955 \mathrm{kcal}$ mol. ${ }^{b}$ Complexation energies (kcal mol) $=E_{c \text { cmplex }}-E_{\text {Hos }}-E_{\text {Guest }}$. 


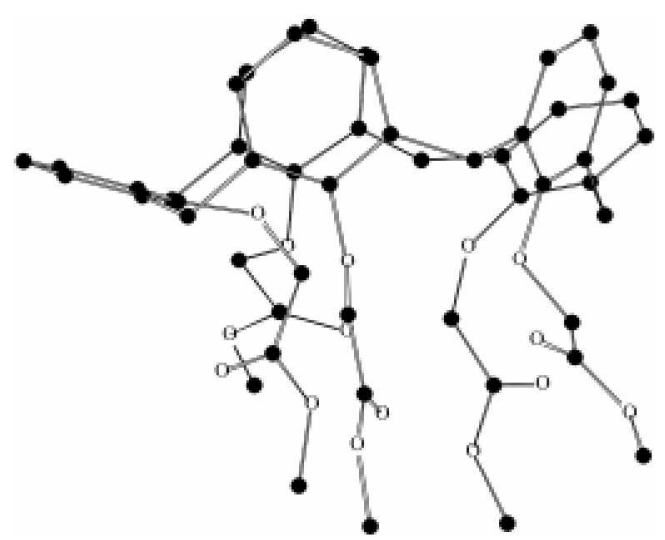

Figure 4. Ab imitio calculated cone contormation of tree host $2 \mathbf{e}$

The $a b$ initio optimized structure for the cone conformation of free host $2 \mathrm{e}$ is depicted in Figure 4. The free host 2e has a somewhat irregular distorted conformation with ester carbonyl functions pointing relatively randomly with respect to the central psendo-cavity of the host. Figures 5(a) through 5 (d) show the $a b$ initio calculated structures of endo-cone-type complex of $\mathbf{2 e}$ with smaller alkyl anmonium cations. in which the hydrogen atoms are omitted for clarity: The structure of host $2 \mathrm{e}$ became more regular upon complexation with ammonium ion. and ester carbonyl functions are pointing toward the interior of the pseudo- cavity of the host molecule. When one sees the structure shown in Figure 5(a), the nitrogen atom in the host-guest $\left(2 \mathrm{e}+\mathrm{NH}_{4}{ }^{-}\right)$complex is located just below the mean plane. which is comprised of five ether-oxy'gen atoms of host $2 \mathrm{e}$ experiencing the intimate interaction with ether oxygen atoms. The structure also implies that there exist multiple hydrogen-bonding interactions between the hydrogen atoms of $\mathrm{NH}_{4}{ }^{-}$and the oxygen atoms of phenol ethers and some of carbonyl groups of ester. These charge-dipole and hydrogen bonding interactions resulted in the lighest stability of the $2 \mathrm{e}+\mathrm{NH}_{+}^{-}$complex among all complexes.

The optimized structures in Figures 5(b) through 6(d). show the nitrogen atom in the $2 \mathrm{e}+\mathrm{RNH}_{3}{ }^{+}$complex situated somewhat above the mean plane of five ether-oxygen atoms of host $2 \mathrm{e}$. With increasing bulkiness of the alkyl groups of the ammonium ion. the ammonium group is progressively located relatively away from the oxygen atoms of phenol ethers. This weakens the interactions between alkyl ammonium guests and oxygen atoms of the host. When we counted the number of hydrogen bonding between the nitrogen atom of alkyl ammonium guests and the etheroxygen atoms of host. we found that most of $\mathrm{RNH}_{3}{ }^{-}$ions use all three hydrogen atoms of ammonium moiety for hydrogen bonding. except for sec- $\mathrm{BuNH}_{3}{ }^{+}$, which uses two hydrogen atoms. tert- $\mathrm{BuNH}_{3}{ }^{-}$uses only one hydrogen atom. with a longer $\mathrm{H}$-bond distance than linear alkyl ammonium ions. A
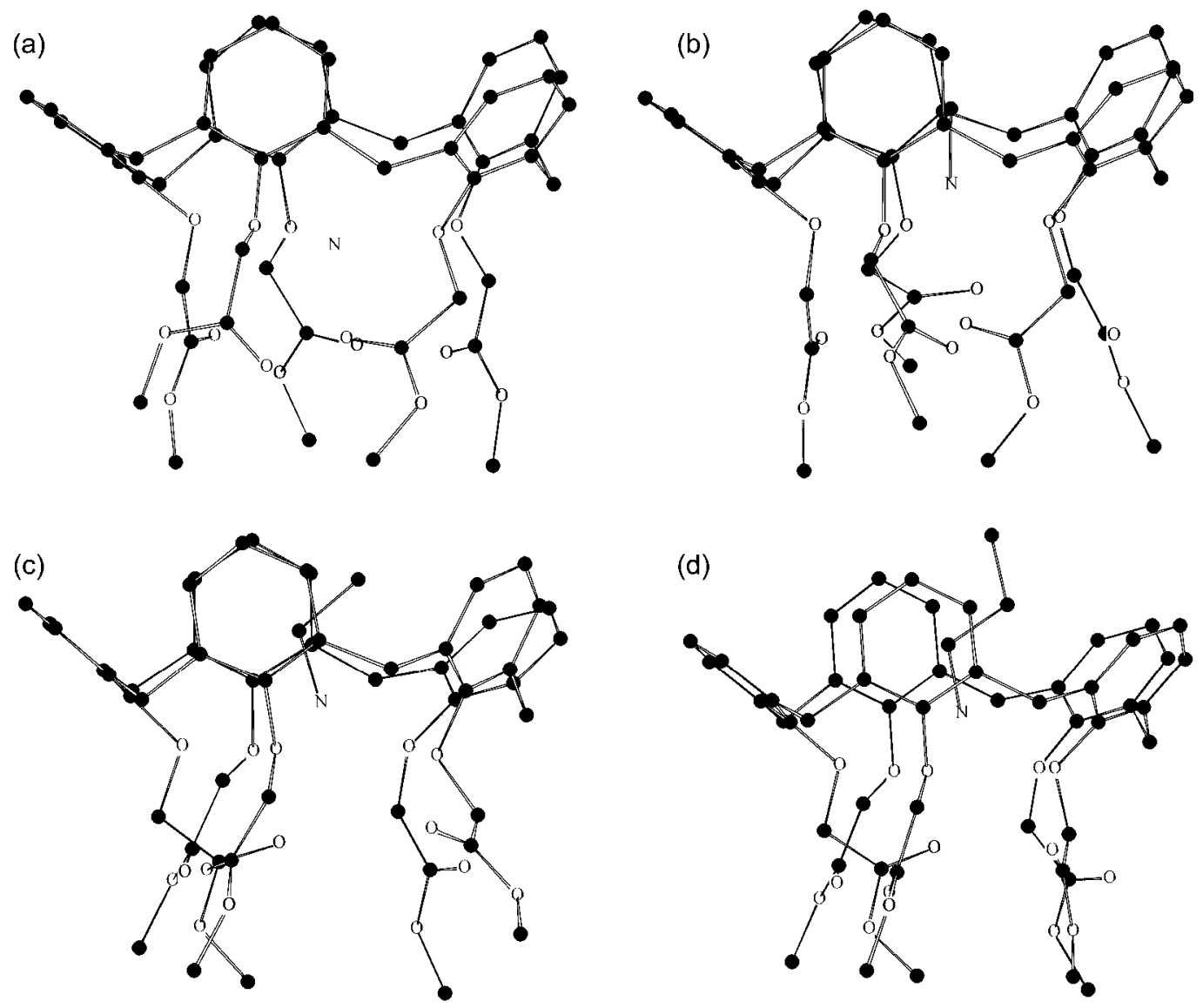

Figure 5. Ab initio calculated endo-cone conformations of $2 \mathrm{e}$ complexed with (a) ammonium, (b) methyl ammonium, (c) ethyl ammonium, and (d) $n$-propyl ammonium ions. 

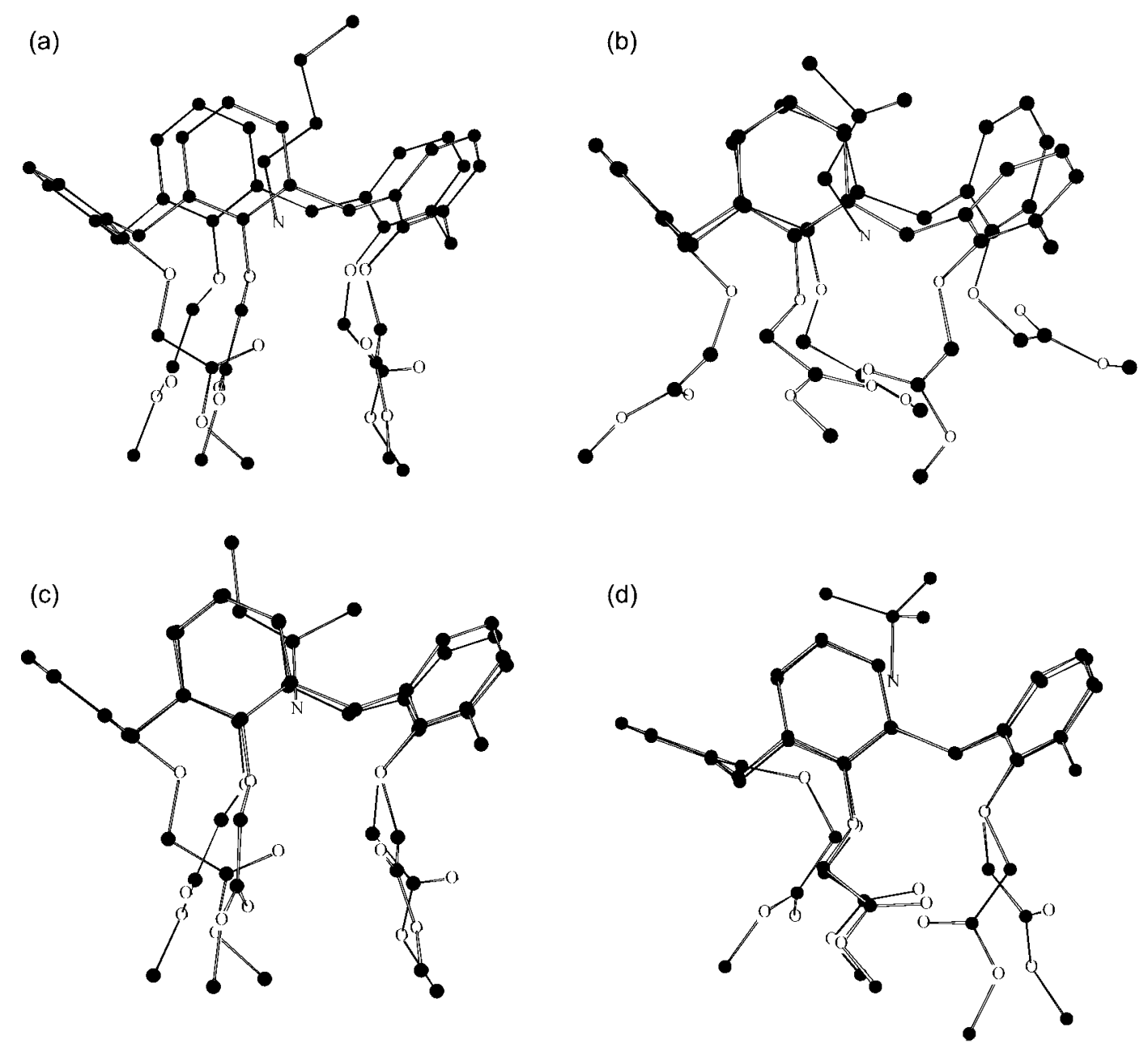

Figure 6. Ab initio calculated endo-cone conformations of $2 \mathrm{e}$ complexed with (a) $n$-butyl ammonium, (b) iso-butyl ammonium, (c) sec-butyl anmoninimn. and (d) tert-butyl anmonium ions.

detailed comparison of the calculated complexation free energies with the distances between the nitrogen atom of butylammonium ion and the mean plane of five etheroxygen atoms of host 1e about four different isomers of butyl ammonium guest ions was reported in previously. ${ }^{15}$

Figures 6 (a) through $6(\mathrm{~d})$ show the $a b$ initio calculated structures of endo-cone-type complex of $2 \mathrm{e}$ with the isomers of butyl ammonium guests. For all the above calculated structures. most of the distances between the nitrogen atom of the guest with the carbonyl oxygen atoms are larger than $5.0 \mathrm{~A}$. far exceeding the usual hydrogen-bonding interaction range of $2.865 \mathrm{~A}$ for the related sy stems. "This fact indicates that there is little influence of the carbonyl oxygen atoms of hosts on the endo-complexation with butyl ammonium guest in the calix[5]arene host molecules studied in this work.

\section{Conclusion}

Using $a b$ initio $\mathrm{HF} / 6-31 \mathrm{G}$ and semi-empirical $\mathrm{AMl}$ quantum mechanics. we have performed computer simulations of the complexation behaviors of the derivatives of calix[5] arene toward a variety of alkyl ammonium ions. For all the calculation results in these simulations. ammonium cation without alkyl group has a much better complexation ability than other alkyl ammonium guests in the order of $\mathrm{NH}_{4}^{+}>$ $\mathrm{MeNH}_{3}{ }^{+}>\mathrm{EtNH}_{3}{ }^{+}>n-\mathrm{PrNH}_{3}^{-} \sim n-\mathrm{BuNH}_{3}^{+}>$iso- $\mathrm{BuNH}_{3}^{+}>$ sec $-\mathrm{BuNH}_{3}{ }^{-}>$tert- $\mathrm{BuNH}_{3}{ }^{-}$. We believe that the present simulations provide a general and useful insight into the molecular recognition behavior of the calix[5]arene derivatives toward alkylammonium guests. which will be applicable for the design of other functional ionophore systems for the recognition of biologically important amines.

Acknowledgment. This research was supported by the Chung-Ang University research grants in 2001. We offer our thanks for the generous time allocation on the supercomputer at the research center for computational science at the Institute for Molecular Science of Japan.

\section{References}

1. Gutsche. C. D. Colizarenes Revisited. The Royal Society of Chemistry: Cambridge. 1998

2. Calixarenes: A Tersatile Class of Aaconctic Conponds. Vicens. J. Böhmer. V. Eds.: Kluwer Academic Publishers: Dordrecht. The Netherlands. 1991.

3. Balzani. V: De Cola. L. Supramolecular Chemism; Kluwer Academic Publishers: Dordrecht. The Netherlands. 1992. 
4. Cation Binding by Hacrocyctes; Inoue. Y. Gokel, G. W. Eds: Marcel Dekker: New York. 1990.

5. (a) Gordon. J. L. M.: Böhmer. V: Vogt. W. Tetrahedron Lett 1995. 36. 2445. (b) Barrett. G.: McKervey. M. A.: Malone. J. F.: Walker. A.: Arnaldd-Nell. F.: Guerra. L.: Schwing-Weill, M.-T. J. Chent. Soc. Perkin Trats. $21993,1475$.

6. Holecular Recognition: Chemical and Biochemical Problents: Roberts. S. M. Ed.: The Proceedings of an International Symposium. Royal Society of Chemistry. Dorset Press: Dorset. Great Britain. 1989.

7. Fages. F.: Desvergne. I.-P.: Kampke. K.: Bouas-Laurent. H.: Lehn. I.-M. Meyer. M.: Albrecht-Gary. A.-M. $J$. Am. Chem. Soc. 1993. 115,3658 .

8. (a) Chang. S.-K.: Hwang. H.-S.: Son. H.: Youk. J.: Kang. Y. S. J. Chem. Soc. Chem. Conmm. 1991. 217. (b) Chang. S.-K.: Jang. M.: Han. S. Y: Lee. J. H.: Kang. M. H: No. K. T. Chem. Leff. 1992. 1937. (c) Han. S. Y.: Kang. M.-H.: Jung. Y. E.: Chang. S.-K. J. Chem. Soc. Perkin Trans. 2 1994. 835.

9. (a) Kubo, Y: Maeda. S.: Tokita. S.: Kubo. M. Nature 1996. 382. 522. (b) Odashima, K.: Yagi, K: Tohda. K.: Unezawa, Y. Andal. Chem. 1993. 65. 1074. (c) Arnecke. R.: Böhmer. V: Cacciapaglia. R.: Cort. A. D.: Mandolini. L. Tetrahedron 1997. 53. 4901.

10. Pappalardo. S.: Parisi. M. F. J. Org. Chem. 1996, 61.8724

11. Amaud-Neu. F: Fuangswasdi, S: Notti. A: Pappalardo, S.:
Parisi, M. Angew: Chent. Int. Ed. 1998.,37, 112.

12. Giannetto. M.: Mori, G.: Notti, A.; Pappalardo, S.; Paris, M. F. Anal Chem 1998. 70. 4631 .

13. Salvo. G. D.: Gattuso. G.: Notti. A.: Parisi. M.: Pappalardo. S. $J$. Org. Chem. 2002. 67.684.

14. Computational Approaches in Suprantolecular Chemistry. Wipft. G.. Ed.: Kluwar Academic Publishers: Dordrecht. The Netherlands, 1994.

15. Choe. J-I.: Chang. S.-K. Bull. Korean Chem. Soc. 2002. 23. 48.

16. (a) Choe. T.-I.: Kim. K.: Chang. S.-K. Bull. Kowan Chem. Soc. 2000. 21. 465. (b) Choe. J.-I:: Chang. S.-K.: Ham. S. W: Nanbu S. Aovagi, M. Bull. Korean Chent Soc. 2001. 22. 1248. (c) Choe. J.-I.; Chang. S.-K.: Nanbu. S. Bull. Korean Chent Soc. 2002, 23. 891.

17. HyperChem Release 6.3: Hypercube. Inc.: Waterloo. Ontario. Canada. 2001

18. Discover Liser's Guide: Biosym Technologies (presently merged to MSI): San Diego, 1999.

19. Notti. A.: Parisi, M. F.: Pappalardo. S. In Calixarenes 200]: Asfari, Z.: Böhmer. V.: Harrowfield. J:- Vicens, J.. Eds.: Kluwer: Dordrecht. 2001: pp 54-70.

20. Jeffiey. G. A. An lnoduction to Hydogen Bonding. Oxford University Press: Onford. 1997: p 67. 